\title{
Role of imaging in evaluation of intestinal obstruction
}

\author{
Mohi J.K. ${ }^{1}$, Kajal S. ${ }^{2}$, Singh T. ${ }^{3}$, Singh J. ${ }^{4}$, Kaur N. ${ }^{5}$ \\ ${ }^{1}$ Dr. Jaswinder Kaur Mohi, Associate Professor, Radiodiagnosis Department GMC, Patiala, ${ }^{2}$ Dr. Sunita Kajal, \\ Consultant, Radiologist, SGHC Hospital, Sohana, Punjab, ${ }^{3}$ Dr. Tejinder Singh, Radiodiagnosis, GMC Patiala, \\ ${ }^{4}$ Dr. Jasvir Singh, Junior Resident, Radiodiagnosis GMC Patiala, ${ }^{5}$ Dr. Navkiran Kaur, Professor and Head of \\ Deptt. Radiodiagnosis, GMC Patiala, Punjab, India.
}

Address for Correspondence: Dr Jasvir Singh, Email: jasvirsingh011789@gmail.com

\begin{abstract}
Introduction: Small bowel obstruction (SBO) is a common clinical entity that occurs secondary to mechanical or functional obstruction of the small gut, preventing normal passage of its contents. It constitutes $20 \%$ of all surgical emergencies for acute abdominal pain and a common cause for hospitalization. Plain abdominal X-ray and ultrasonography were used for initial examination. Now, Computed tomography is the modality of choice for preoperative evaluation of SBO. Aims and Objectives: To evaluate the diagnostic accuracy of various imaging modalities namely plain x-rays of abdomen, ultrasound and computed tomography in the diagnosis of intestinal obstruction with reference to a) The presence or absence of obstruction b) The level of obstruction

c) The cause of obstruction. Materials and Methods: It was a hospital based prospective study in which X-Ray and ultrasonography were done as an initial modality for screening and Multi Detector Computed Tomography (MDCT) scan was done later on for detailed evaluation. Relevant history, clinical examination and routine investigations were done. Results: Acute intestinal obstruction: CT scan was found to be superior in predicting a fully correct diagnosis $(78 \%)$ when compared to ultrasound $(29 \%)$ which in turn was found to be superior to plain films which provided fully correct diagnosis only in $10 \%$ of the cases. Subacute intestinal obstruction- In $62.5 \%$ cases of sub acute intestinal obstruction CT scan provide fully correct diagnosis whereas in none of the cases did ultrasound or plain films provide fully correct diagnosis. Conclusion: CT was found to be superior to ultrasound and plain films in finding out the presence, level as well as cause of obstruction.
\end{abstract}

Keywords: Intestinal obstruction, Ultrasound, X ray, Computed tomography.

\section{Introduction}

Intestinal obstruction is a frequent surgical emergency. Effective management depends upon early and accurate diagnosis. A comprehensive diagnostic approach includes history, physical examination and radiological investigation [1]. Bowel obstruction is a relative common condition.

From 3 to $20 \%$ of emergency surgical admissions and as many as 25 to $35 \%$ of admissions for acute abdominal disorders involve intestinal obstruction, out of which small bowel obstruction accounts for $12-16 \%$. If all the cases of intestinal obstruction are considered, the small bowel alone is involved in $60-80 \%$ and large bowel in $20-30 \%$ [2].

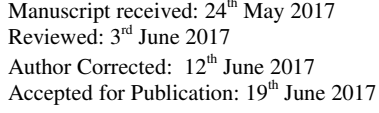

Intestinal obstruction may be classified into two types:

- Dynamic: where peristalsis is working against a mechanical obstruction.

- Adynamic: this may occur is two forms. Perstalsis may be propulsive form (e.g. mesenteric vascular

- Occlusion or pseudo-obstruction). In both types a mechanical element in absent [3].

Secondary Mechanical SBO occurs whenever there is an intrinsic or extrinsic blockage of the normal flow of bowel contents. It represents a frequent cause of acute abdomen The most common cause of SBO in developed countries is adhesions from surgery. Strangulated hernias remain the most 
common cause of intestinal obstruction in underdeveloped countries. SBO typically produces gaseous distention of the bowel loops proximal to the obstructing lesion. Dilated loops of the small intestine usually can be recognized within 3-5 hours after the onset of complete obstruction [4].

If the obstructing lesion is somewhat distal, as more loops of bowel become distended with air, they may appear to be stacked on top of each other in a characteristic "stepladder" configuration [5].

The dilatation of the small bowel stimulates the mucosa to secrete fluid.[6] Thus, the distended bowel contains varying amounts of air and fluid. This accounts for the air-fluid interfaces seen on horizontal- beam radiographs. As the small bowel dilates, the valvulae conniventes widen, and this causes the small bubbles of air to become trapped. In some instances (approximately 6\%) of SBO, little or no air is present and the distended bowel loops are predominantly fluid filled [7].

Sonography is not commonly used for the evaluation of SBO mainly because most of the time the bowel loops are filled with gas, producing nondiagnostic sonograms and because adhesions, the most common cause of mechanical SBO, are not detected with this technique.[8] However, when the obstructed bowel segments are dilated and filled with fluid, not only can the level of obstruction be recognized but the cause of the obstruction can also be demonstrated by using the fluid filled bowel as a sonic window $[8,9]$.

Several studies have demonstrated the value of CT in confirming the diagnosis (site and level) and revealing the cause of small bowel obstruction, with a sensitivity of $94 \%-100 \%$ and an accuracy of $90 \%-95 \%[10,11]$

Plain abdominal radiography- The key radiographic signs that allow distinction between a high-grade SBO and a low-grade obstruction are the presence of small bowel distension, with maximal dilated loops averaging $36 \mathrm{~mm}$ in diameter and exceeding $50 \%$ of the calibre of the largest visible colon loop as well as a 2.5 times increase in the number of distended loops in the abdomen compared with the normal number. Other findings that are most significant and predictive of high-grade SBO, according to experienced gastrointestinal radiologists,[11] are the presence of more than two air-fluid levels, air-fluid levels wider than $2.5 \mathrm{~cm}$, and air-fluid levels differing more than $2 \mathrm{~cm}$ in height from one another within the same small bowel loop [12].

Sonography- At sonography, bowel obstruction is considered to be present when the lumen of the fluid filled small bowel loops is dilated to more than $3 \mathrm{~cm}$, the length of the segment is more than $10 \mathrm{~cm}$, and peristalsis of the dilated segment is increased, as shown by the to-and-fro or whirling motion of the bowel contents $[8,14,15]$.

Computed tomography- CT criteria for SBO are the presence of dilated small bowel loops (diameter $>2.5 \mathrm{~cm}$ from outer wall to outer wall) proximally to normal-caliber or collapsed loops distally [16].

In the present study we wish to determine the role of different radiological modalities namely plain films of abdomen, ultrasound and computed tomography in the diagnostic evaluation of intestinal obstruction.

\section{Material and Methods}

Study was carried out in department of RadioDiagnosis, Rajindra Hospital, Patiala. In our study, we included 60 patients referred to Department of Radio-Diagnosis, Rajindra Hospital, Patiala with clinical suspicion of intestinal obstruction. All patients were subjected to detailed history taking, clinical examination and routine laboratory investigations and were subjected to plain radiographs of abdomen both supine and erect views, ultrasound examination and computed tomography. These were interpreted individually and were compared with the final diagnosis which was obtained either by surgery or intervention, or contrast studies and follow up. The permission for conducting the study from hospital ethical advisory committee was obtained.Detailed consent performa was also filled at the time of conducting the study.

Plain radiographs of the abdomen, both supine and erect views were taken and were evaluated for the presence of obstruction by noting the dilated bowel loops and fluid levels and their distribution.

On ultrasound we evaluated for distended fluid filled bowel loops, stasis of intestinal contents, decreased or increased bowel motility. 
CT scans were interpreted for the presence or absence of obstruction as well as possible etiology of obstruction. Obstruction was considered to be present when dilated bowel loops were seen proximally and collapsed or normal caliber bowel distally.

The point of transition was studied for evaluating cause of obstruction.

\section{X- ray Machine: 300MA Allenger company}

Ultrasound Machine: Ultrasound was performed with Philips Envisor or GE Logiq $\alpha-200$ with a $3.5 \mathrm{mhz}$ sector or curvilinear probes.

CT Machine: Siemens- Somatom Emotion 6 slice third generation spiral CT.

Contrast material: Non-ionic contrast (e.g.iohexol) was used in our study. Contrast was given by peripheral i.v. route and oral route. Continuous monitoring of the vital parameters was done during contrast injection.
Evaluation and statistical analysis- The data regarding the presence or absence of obstruction, level of obstruction and cause of obstruction for plain X-ray, Ultrasound and CT was obtained by comparing it with the final diagnosis in each case. The results were analyzed by using the following statistical measures.

a. Presence/Absence of Obstruction

1. Sensitivity $=$ true positive $/$ total no of positive $X$ 100

2. Specificity $=$ true negative $/$ total no. of negative X 100

3. Accuracy $=$ true positive + true negative $/$ total no of positive + negative $\mathrm{X} 100$

b. Level of Obstruction $=$ no. of cases in which level was correctly identified / total no of cases X 100.

c. Cause of obstruction $==$ no. of cases in which cause was correctly identified / total no of cases X 100.

\section{Results}

The study comprised of 60 patients who presented with clinical suspicion of intestinal obstruction to Rajindra hospital, Patiala and referred to Radiodiagnosis department for diagnostic work up.

Plain x-ray of abdomen was performed both in the erect and supine positions. Ultrasound of abdomen was performed in all patients. CT scanning of the patients was done in the manner elucidated previously.

Of the 60 patients presented with suspected intestinal obstruction, 57 proved to have intestinal obstruction (acute intestinal obstruction- 41 , subacute intestinal obstruction -16)

Maximum number of patients presenting with intestinal obstruction were of age group 41-50yrs. The youngest patient in the present study was less than 20 yrs old whereas the oldest patient was more than 60 yrs. Males were seen to be more frequently involved as compared to females

(M:F ratio is 1.7:1). Pain abdomen was seen in all patients with suspected clinical obstruction (100\%). Vomiting and abdominal distension was seen in $73 \%$ of the cases.

Table-1: Pattern of Intestinal Obstruction.

\begin{tabular}{|c|c|c|c|}
\hline Type of Obstruction & $\begin{array}{c}\text { Small intestinal } \\
\text { obstruction (SBO) }\end{array}$ & Large bowel obstruction (LBO) & Total \\
\hline Acute intestinal obstruction & 28 & 13 & 41 \\
\hline Subacute intestinal obstruction & 14 & 2 & 16 \\
\hline Total & & & $\mathbf{5 7}$ \\
\hline
\end{tabular}

Out of total cases of intestinal obstruction, $72 \%$ presented with acute intestinal obstruction and $28 \%$ presented with subacute intestinal obstruction. 
Table-2: Aetiology of acute intestinal obstruction.

\begin{tabular}{|c|c|c|c|c|c|}
\hline Etiology & \multicolumn{2}{|l|}{$\begin{array}{l}\text { Small intestinal obstruction (SBO) } \\
(\mathrm{n}=\mathbf{2 8})\end{array}$} & \multicolumn{2}{|l|}{$\begin{array}{l}\text { Large bowel obstruction (LBO) } \\
(n=13)\end{array}$} & \multirow{2}{*}{$\begin{array}{c}\begin{array}{r}\text { Total } \\
(\mathbf{n}=\mathbf{4 1})\end{array} \\
17\end{array}$} \\
\hline Malignancy & - Distal SBO due to Ca ovary (6) & 6 & $\begin{array}{l}\text { - Carcinoma Colon (hepatic Flexure } \\
\text { (2), ascending Colon (3), sigmoid } \\
\text { colon (3) (Figure } 1,2 \text { and } 3 \text { ) } \\
\text { - Carcinoma gallbladder infiltrating } \\
\text { into Hepatic Flexure (3) }\end{array}$ & 11 & \\
\hline Inflammatory & $\begin{array}{l}\text { - Proximal SBO due to TB (5), } \\
\text { Appendicitis with adhesions (3), } \\
\text { Appendicular abscess (2), Pelvic } \\
\text { abscess (1), Right Paracolic } \\
\text { Abscess (2) }\end{array}$ & 13 & 0 & & 13 \\
\hline Adhesions & - Distal SBO & 6 & 0 & & 6 \\
\hline Volvulus & - Small bowel Volvulus & 2 & - Sigmoid Volvulus & 1 & 3 \\
\hline Intussusceptions & - Jejuno jejunal & 1 & - Colocolic & 1 & 2 \\
\hline
\end{tabular}

Accuracy of plain X-ray, Ultrasound and CT findings- The final diagnosis obtained at surgery/ intervention/contrast studies and follow up was compared with the diagnosis made by X-ray, Ultrasound and CT. To correlate with the accuracy of X-ray, Ultrasound and CT, it is divided into 3 groups FC (fully correct), $\mathrm{PC}$ (partially correct) and NC (not correct).

FC- Fully correct -obstruction and cause detected.

PC- Partially correct- obstruction detected but not the cause

NC- not correct- obstruction not correct

Table-3: Accuracy of plain X-RAY findings.

(a) Acute Intestinal obstruction.

\begin{tabular}{|c|c|c|c|c|}
\hline \multirow{2}{*}{ Etiology } & \multicolumn{4}{|c|}{ Acute Intestinal obstruction } \\
\cline { 2 - 5 } & No. & FC & PC & NC \\
\hline Malignancy & 17 & 3 & 10 & 4 \\
\hline Inflammatory & 13 & 0 & 13 & 0 \\
\hline Adhesions & 6 & 0 & 6 & 0 \\
\hline Vovulus & 3 & 1 & 2 & 0 \\
\hline Intussusceptions & 2 & 0 & 2 & $\mathbf{4}$ \\
\hline Total & $\mathbf{4 1}$ & $\mathbf{4}$ & $\mathbf{3 3}$ & \\
\hline
\end{tabular}

(b) Sub acute Intestinal obstruction

\begin{tabular}{|c|c|c|c|c|}
\hline \multirow{2}{*}{ Etiology } & \multicolumn{4}{|c|}{ Sub acute Intestinal obstruction } \\
\cline { 2 - 5 } & No. & FC & PC & NC \\
\hline Malignancy & 3 & 0 & 0 & 6 \\
\hline Stricture & 12 & 0 & 6 & 1 \\
\hline Foreign body & 1 & 0 & 0 & $\mathbf{1 0}$ \\
\hline Total & $\mathbf{1 6}$ & $\mathbf{0}$ & $\mathbf{6}$ & 3 \\
\hline
\end{tabular}

Among the cases of acute intestinal obstruction, plain films provided a fully correct diagnosis in 4 cases (10\%), which included 3 cases of mass in ascending colon and 1 case of sigmoid volvulus. In 33 cases $(80 \%)$ the plain film diagnosis was partially correct. 
Out of 60 cases with clinically suspected intestinal obstruction, plain X-ray correctly diagnosed presence/absence of obstruction in 45 cases (75\%). Among 57 patients with intestinal obstruction, level of obstruction was correctly predicted by plain X-ray in 48 cases $(84 \%)$.

Table-4: Diagnosis of cause of obstruction by X-RAY.

\begin{tabular}{|c|c|c|}
\hline Type & Correct & Incorrect \\
\hline Acute intestinal obstruction (41) & 4 & 37 \\
\hline subacute intestinal obstruction (16) & 0 & 16 \\
\hline Total (57) & 4 & 53 \\
\hline No obstruction (3) & 2 & 1 \\
\hline Total (60) & $\mathbf{6}$ & $\mathbf{5 4}$ \\
\hline
\end{tabular}

Table-5: Accuracy of Ultrasound findings

\begin{tabular}{|c|c|c|c|c|}
\hline \multirow{2}{*}{ Etiology } & \multicolumn{4}{|c|}{ Acute Intestinal obstruction } \\
\cline { 2 - 5 } & No. & FC & PC & NC \\
\hline Malignancy & 17 & 5 & 12 & 0 \\
\hline Inflammatory & 13 & 4 & 5 & 4 \\
\hline Adhesions & 6 & 0 & 6 & 0 \\
\hline Vovulus & 3 & 1 & 2 & 0 \\
\hline Intussusception & 2 & 2 & 0 & $\mathbf{4 ( 1 0 \% )}$ \\
\hline Total & $\mathbf{4 1}$ & $\mathbf{1 2}(\mathbf{2 9} \%)$ & $\mathbf{2 5 ( 6 1 \% )}$ & $\mathbf{4} \%$ \\
\hline
\end{tabular}

\begin{tabular}{|c|c|c|c|c|}
\hline \multirow{2}{*}{ Etiology } & \multicolumn{4}{|c|}{ Subacute Intestinal obstruction } \\
\cline { 2 - 5 } & No. & FC & PC & NC \\
\hline Malignancy & 3 & 0 & 0 & 3 \\
\hline Stricture & 12 & 0 & 9 & 3 \\
\hline Foreign body & 1 & 0 & 0 & 1 \\
\hline Total & 16 & 0 & $9(56 \%)$ & $7(43 \%)$ \\
\hline
\end{tabular}

Out of 41 cases of acute intestinal obstruction, USG correctly diagnose $37(90.2 \%)$ and out of 16 cases of subacute intestinal obstruction, USG correctly diagnose $9(56.2 \%)$ cases.

Table-6: Accuracy of CT findings.

\begin{tabular}{|c|c|c|c|c|}
\hline \multirow{2}{*}{ Etiology } & \multicolumn{4}{|c|}{ Acute Intestinal obstruction } \\
\cline { 2 - 5 } & No. & FC & PC & NC \\
\hline Malignancy & 17 & 11 & 6 & 0 \\
\hline Inflammatory & 13 & 10 & 3 & 0 \\
\hline Adhesions & 6 & 6 & 0 & 0 \\
\hline Vovulus & 3 & 3 & 0 & 0 \\
\hline Intussusception & 2 & 2 & 0 & $\mathbf{0}(\mathbf{0 \%})$ \\
\hline Total & $\mathbf{4 1}$ & $\mathbf{3 2}(\mathbf{7 8 \%})$ & $\mathbf{9 ( 2 1 \% )}$ & $\mathbf{2}$ \\
\hline
\end{tabular}

\begin{tabular}{|c|c|c|c|c|}
\hline \multirow{2}{*}{ Etiology } & \multicolumn{4}{|c|}{ Subacute Intestinal obstruction } \\
\cline { 2 - 5 } & No. & FC & PC & NC \\
\hline Malignancy & 3 & 0 & 0 & 3 \\
\hline Stricture & 12 & 9 & 0 & 3 \\
\hline Foreign body & 1 & 1 & 0 & 0 \\
\hline Total & 16 & $10(62.5 \%)$ & $0(0 \%)$ & $6(37 \%)$ \\
\hline
\end{tabular}


Table-7: Diagnosis of presence/ absence of obstruction by CT

\begin{tabular}{|c|c|c|}
\hline Type & Correct & Incorrect \\
\hline Acute intestinal obstruction (41) & 41 & 0 \\
\hline subacute intestinal obstruction (16) & 10 & 6 \\
\hline No obstruction (3) & 3 & 0 \\
\hline Total (60) & $\mathbf{5 4}$ & $\mathbf{6}$ \\
\hline
\end{tabular}

Table-8: Relative accuracy of CT scan, Ultrasound AND X-ray.

\begin{tabular}{|c|c|c|c|c|c|c|}
\hline \multirow{2}{*}{} & \multicolumn{3}{|c|}{ Acute intestinal obstruction } & \multicolumn{2}{c|}{ Subacute intestinal obstruction } \\
\cline { 2 - 7 } & FC & PC & NC & FC & PC & NC \\
\hline \multirow{3}{*}{ CT scan } & 32 & 9 & 0 & 10 & 0 & 6 \\
\cline { 2 - 7 } & $78 \%$ & $21 \%$ & $0 \%$ & $62.5 \%$ & $0 \%$ & $37 \%$ \\
\hline \multirow{2}{*}{ Ultrasound } & 12 & 25 & 4 & 0 & 9 & 7 \\
\cline { 2 - 7 } & $29 \%$ & $61 \%$ & $10 \%$ & $0 \%$ & $56 \%$ & $43 \%$ \\
\hline \multirow{2}{*}{ CXR } & 4 & 33 & 4 & 0 & 6 & 10 \\
\cline { 2 - 7 } & $10 \%$ & $80 \%$ & $10 \%$ & $0 \%$ & $37.5 \%$ & $62.5 \%$ \\
\hline
\end{tabular}
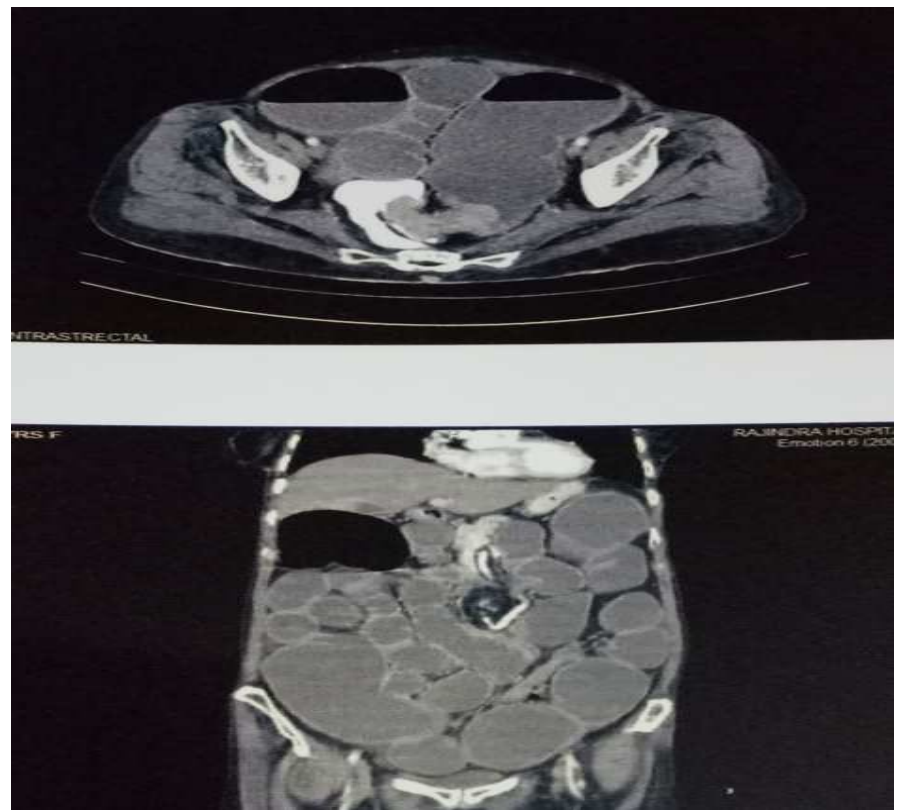

Figure-1: Contrast enhanced coronal CT images showing heterogeneously enhancing mass at rectosigmoid region with proximal dilated gut loops

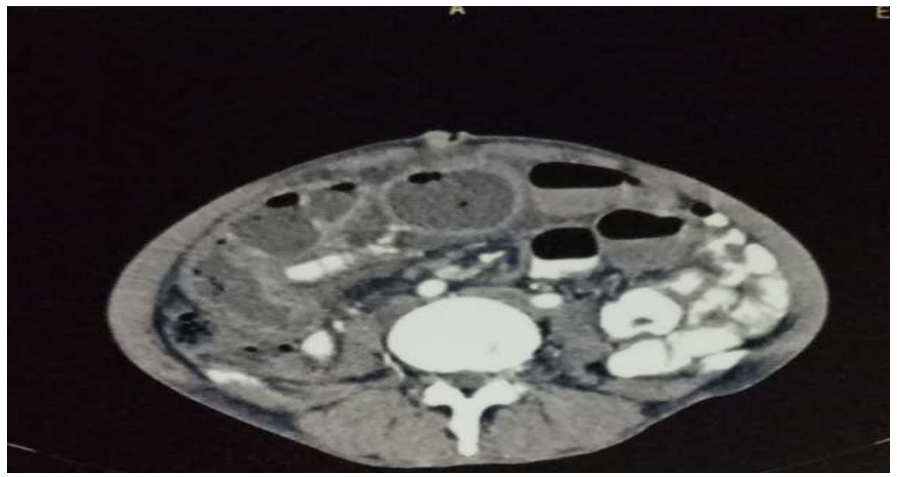

Figure-2: Axial contrast enhanced CT image shows thickened and dilated gut coils with target sign and ascites 

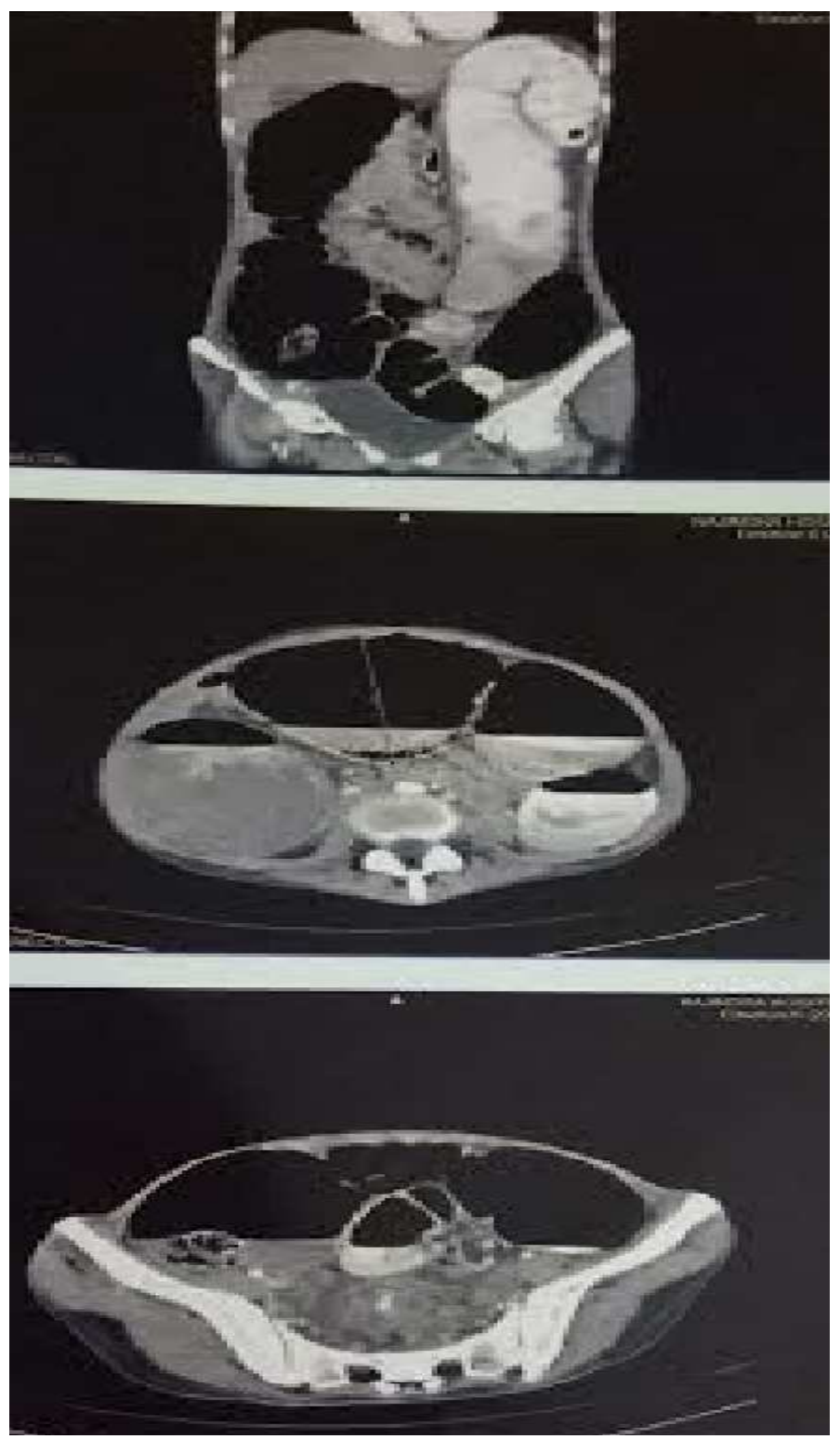

Figure-3: Contrasted enhanced axial and coronal CT images shows marked dilatation of large bowel loops in a patient with carcinoma of sigmoid colon

\section{Discussion}

Small bowel obstruction is much more common than large bowel obstruction. In the present study also, small bowel obstruction was seen in $74 \%$ compared to large bowel obstruction seen in $26 \%$ of patients. Shekeeb et al [14] studied one hundred seventy one cases of mechanical intestinal obstruction. One hundred fifteen had small bowel obstruction and fifty six had large bowel obstruction.

Markogiannakis et al [15] included 150 consecutive patients in the study, 114(76\%) presented with small bowel obstruction and 36 (24\%) with large bowel obstruction. In the present study the commonest cause of SBO was found to be due to inflammatory causes which included tuberculosis in most of the cases. Malignancy was the second most common cause.

In an Indian study conducted by Vaidya and Sodhi [16] (1978), out of 102 cases of GIT tuberculosis, 81 patients experienced obstructive symptoms and 62 had radiological evidence of obstruction. The incidence of tuberculosis leading to bowel obstruction in the present study indirectly reflects the high prevalence of tuberculosis in India. 
The commonest clinical feature of intestinal obstruction in the present study was pain abdomen in all, followed by vomiting and abdominal distension.

This was similar to the study by Stanil and et al [17] and Chandle et al [18] who have reported pain abdomen in $92-100 \%$, vomiting in $82-91 \%$ and abdominal distension in $59-70 \%$ of cases of SBO.

Burdett et al [19] (1961) reported pain abdomen in 100\%, distension in $85 \%$ and vomiting in $60 \%$ in cases of LBO.

Plain X-ray in intestinal obstruction- Plain X-ray remains the primary step in evaluation of bowel obstruction. Supine and erect abdominal radiographs show dilated coils of gut, air fluid levels and pattern of distribution in intestines. The more the dilated loops, more distal is the level of obstruction. In the dilated small bowel which is almost fluid filled small bubbles of gas may be trapped in rows between the valvulae coniventies- 'string of beads' sign and is virtually diagnostic of small bowel obstruction, in the case of colonic obstruction, there is a large dilated colon proximal to the obstruction.

The probability of making the correct diagnosis of presence of obstruction on plain radiograph of abdomen varies from $70-80 \%$ in most of the studies.

Table-9: Sensitivity of plain films in intestinal obstruction.

\begin{tabular}{|c|c|}
\hline & Sensitivity of plain films \\
\hline Fukuya et al[20] (1992) & $80 \%$ \\
\hline Ko et al[21] (1993) & $71 \%$ \\
\hline Suri et al[22] (1999) & $77 \%$ \\
\hline Present study & $75 \%$ \\
\hline
\end{tabular}

KO et al[21] (1993) reported the efficacy of plain films in diagnosis of presence of obstruction to be $71 \%$, level of obstruction to be $51 \%$ and cause of obstruction to be $2 \%$.

Suri et al [22] (1999) showed sensitivity of plain films in diagnosis of presence of obstruction to be $77 \%$, level of obstruction to be $60 \%$ on plain films.

In the present study also intestinal obstruction could be diagnosed on the basis of plain X-rays in $75 \%$ of cases (43/57). Cases where obstruction was not picked up by plain X-rays included 4 cases of acute intestinal obstruction and 10 cases of subacute intestinal obstruction. Among 57 patients with intestinal obstruction, level of obstruction was correctly predicted in 13 patients. In 9 cases it could not predict the level correctly. These included 2 cases of large bowel obstruction due to carcinoma of hepatic flexure which was interpreted as distal SBO as the right sided colon was fluid filled and devoid of air. Another 2 cases of distal SBO due to adhesion were interpreted as LBO because of hugely dilated small bowel loops which mimicked large bowel loops. 5 cases of distal SBO were misinterpreted as proximal SBO. CXR in general is considered to be poor modality for detection of underlying etiology of intestinal obstruction due to lack of specific features. In the present study, the cause of obstruction was correctly diagnosed in 4 cases only-3 cases of carcinoma of ascending colon suggested by a soft tissue mass in the dilated in ascending colon with obstruction and one case of sigmoid volvulus suggested by the characteristics 'coffee bean' sign. Plain films were found to be superior in acute intestinal obstruction compared to subacute intestinal obstruction regarding the detection of presence of obstruction $(90 \% \mathrm{v} / \mathrm{s} 37.5 \%)$, level of obstruction $(83 \% \mathrm{v} / \mathrm{s} 87.5 \%)$ as well as the cause of obstruction $(9 \% \mathrm{v} / \mathrm{s}$ none).

Fully correct diagnosis was predicted in only in $9 \%$ of the cases in acute intestinal obstruction whereas no correct diagnosis was predicted in subacute intestinal obstruction. Among 41 cases of acute intestinal obstruction, plain X-ray diagnosed correctly the presence of obstruction in 37 cases $(90 \%)$. Out of the 16 cases of sub acute intestinal obstruction, plain X-ray diagnosed obstruction in 6 cases $(37.5 \%)$. Out of 41 cases of 
acute intestinal obstruction, plain X-ray correctly diagnosed level of obstruction in 34 cases (83\%). Out of 16 cases of subacute intestinal obstruction, plain X-ray correctly diagnosed level of obstruction in 14 cases $(87.5 \%)$.

Ultrasound in intestinal obstruction- Ultrasound is used as initial investigation in most cases of acute abdominal disorders. It has marked limitations in the investigation of GI tract because of air in bowel leading to poor sound transmission and scattering of ultrasound beams. The hallmarks of intestinal obstruction on ultrasound are the dilated coils of gut, filled with fluid. Specific mucous membrane stricture present conclusive evidence as to the obstruction site. Jejunal segments are identified by typical stepladder echoes with in the intestinal lumen caused by kerckring folds observed at the interval of $2-3 \mathrm{~mm}$. the ileum is characterized by naked mucosal pattern, whereas colon is recognized by the typical haustration pattern.

Table-10: Comparison of sensitivity of ultrasound of previous studies with present study.

\begin{tabular}{|c|c|c|c|}
\hline & Sensitivity & Level & Cause \\
\hline Ko et al[21] (1993) & $89 \%$ & $76 \%$ & $20 \%$ \\
\hline Suri et al[22] (1999) & $83 \%$ & $70 \%$ & $23 \%$ \\
\hline Present study & $80 \%$ & $84 \%$ & $21 \%$ \\
\hline
\end{tabular}

In the present study ultrasound could detect the presence of obstruction in $80 \%$ of the cases (46/57). Ko et al [21] reported the efficiency of ultrasound in detecting the level of obstruction to be $76 \%$. Suri et al [22] reported the efficiency of ultrasound in detecting presence of obstruction in $83 \%$ and the level of obstruction to be $70 \%$. In present study ultrasound could diagnose the level of obstruction correctly in $84 \%$ of cases (48/57 cases).

CT in intestinal obstruction- As CT can evaluate bowel, mesentry and the retroperitoneal area at the same time, it is useful for evaluating abdominal diseases. Studies have shown that CT can provide more information about the cause of obstruction than do plain films/contrast/ultrasound.

CT reveals extra luminal masses such as tumors and abscess that may cause obstruction. Intramural abnormalities can be better identified on CT scans.

Table-11: Comparison of sensitivity of computed tomography of present study with previous studies

\begin{tabular}{|c|c|c|c|}
\hline & Sensitivity & Specificity & Cause \\
\hline Megibow et al[23] & $94 \%$ & $96 \%$ & $73 \%$ \\
\hline Suri et al[22] & $93 \%$ & $100 \%$ & $77 \%$ \\
\hline Present study & $89 \%$ & $100 \%$ & $73.6 \%$ \\
\hline
\end{tabular}

Megibow et al [23] showed that CT had sensitivity of 94\% and specificity of $96 \%$. Suri et al [22] showed that CT had sensitivity of $93 \%$ and specificity of $100 \%$. In present study CT showed overall sensitivity of $90 \%$ and specificity of $100 \%$ in diagnosis of intestinal obstruction.

CT diagnosed level of obstruction in all cases of acute and subacute intestinal obstruction. The cause of obstruction was correctly detected by CT in $42 / 57$ cases $(73.6 \%)$. The cases where CT could not pickup the cause correctly included 9 cases of malignancy, 3 cases of tuberculosis and 3 cases of appendicitis. In 5 cases the growth at heptic flexure could not be picked up due to inadequate opacification of large bowel. CT scan could not pick up the metastatic stricture of small bowel from carcinoma ovary.

CT scan could correctly diagnose obstruction due to tuberculosis in 9 out of 12 cases. The findings included mural thickening of bowel wall with narrowed lumen, mesenteric and omental thickening, mesenteric lymphadenopathy, disorganized appearance of soft tissue density masses and bowel loops and ascites.

CT scan is highly accurate in the detection of intraabdominal abscesses with a reported accuracy of 95-100\%. In the present study all the 5 cases of abscesses were diagnosed correctly. 


\section{Conclusion}

In acute intestinal obstruction-CT was found to be superior to ultrasound and plain films in finding out the presence, level as well as cause of obstruction. Ultrasound was superior to plain films in the evaluation of cause of obstruction. Both have similar accuracy in predicting the presence and level of obstruction

In subacute intestinal obstruction- CT was found to be superior to ultrasound and plain films especially in evaluating the cause of obstruction. Ultrasound was superior to plain films in evaluating the presence of obstruction. Ultrasound and X-ray have similar accuracy in predicting the level of obstruction.

Funding: Nil, Conflict of interest: None Permission of IRB: Yes

\section{References}

1. Shakil O, Zafar SN, Zia-ur-Rehman, Saleem S, Khan R, Pal KMI. The role of computed tomography for identifying mechanical bowel obstruction in a Pakistani population. J Pak Med Assoc 2011; 61:871.

2. Maglinte DD, Heitkamp DE, Howard TJ, Kelvin FM, Lappas JC. Current concepts in imaging of small bowel obstruction. Radiol Clin North Am. 2003 Mar;41(2):263-83, vi.

3. Russell R.C.G., Williams NS, Bulstrode CJK, Bailey H. Bailey \& Love's Short Practice of Surgery. Intestinal Obstruction. $24^{\text {th }}$ edn. 2004; 1186.

4. Herlinger $\mathrm{H}$, Maglinte DDT. Plain film radiography. In: Herlinger $\mathrm{H}$, Maglinte DDT, eds. Clinical radiology of the small intestine. Philadelphia, Pa: Saunders, 1989; 49-53.

5. Eisenberg RL. Gastrointestinal radiology: a pattern approach. Philadelphia, Pa: Lippincott-Raven, 1996;3: 421-31.

6. Nevitt PC. The string of pearls sign. Radiology. 2000 Jan;214(1):157-8.

7. WILLIAMS JL. Fluid-filled loops in intestinal obstruction. Am J Roentgenol Radium Ther Nucl Med. 1962 Oct;88:677-86.
8. Lim JH. Intestinal obstruction. In: Maconi G, Porro GB, eds. Ultrasound of the gastrointestinal tract. Berlin, Germany: Springer-Verlag, 2007; 27-34.

9. Maglinite DD, Howard TJ, Lillemoe KD, Sandrasegaran K, Rex DK. Small bowel obstruction: state of the art imaging and its role in clinical management. Clin Gastroenterol Hepatol 2008; 6(2):130-39.

10. Maglinte DD, Gage SN, Harmon BH, Kelvin FM, Hage JP, Chua GT, Ng AC, Graffis RF, Chernish SM. Obstruction of the small intestine: accuracy and role of CT in diagnosis. Radiology. 1993 Jul;188(1):61-4.

11. Frager D, Medwid SW, Baer JW, Mollinelli B, Friedman M. CT of small-bowel obstruction: value in establishing the diagnosis and determining the degree and cause. AJR Am J Roentgenol. 1994 Jan; 162(1):37-41.

12. Lappas JC, Reyes BL, Maglinte DD. Abdominal radiography findings in small-bowel obstruction: relevance to triage for additional diagnostic imaging. AJR Am J Roentgenol. 2001 Jan; 176(1):167-74.

13. Thompson WM, Kilani RK, Smith BB, Thomas J, Jaffe TA, Delong DM, Paulson EK. Accuracy of abdominal radiography in acute small-bowel obstruction: does reviewer experience matter? AJR Am J Roentgenol. 2007 Mar;188(3):W233-8.

14. Wilson SR. The gastrointestinal tract. In: Rumack CM, Wilson SR, Charboneau JW, eds. Diagnostic ultrasound. $3^{\text {rd }}$ ed. St Louis, Mo: Mosby, 2005; 269-20.

15. Meiser G, Meissner K. [Sonographic differential diagnosis of intestinal obstruction-results of a prospective study of 48 patients]. Ultraschall Med. 1985 Feb;6(1):39-45.

16. Fukuya T, Hawes DR, Lu CC, Chang PJ, Barloon TJ. CT diagnosis of small-bowel obstruction: efficacy in 60 patients. AJR Am J Roentgenol. 1992 Apr; 158 (4):765-9; discussion 771-2. 
17. Vaidya MG, Sodhi JS. Gastrointestinal tract tuberculosis: a study of 102 cases including 55 hemicolectomies. Clin Radiol. 1978 Mar; 29 (2): 189-95.

18. Staniland JR, Ditchburn J, De Dombal FT. Clinical presentation of acute abdomen: study of 600 patients. Br MedJ.1972 Aug 12;3(5823):393-8.

19. Cheadle WG, Garr EE, Richardson JD. The importance of early diagnosis of small bowel obstruction. Am Surg. 1988 Sep;54(9):565-9.

20. Burdett JW, Stevens LL. The clinical management of intestinal obstruction. Arch surg 1961;83:134-45.
21. Ko YT, Lim JH, Lee DH, Lee HW, Lim JW. Small bowel obstruction: sonographic evaluation. Radiology. 1993 Sep;188(3):649-53.

22. Suri S, Gupta S, Sudhakar PJ, Venkataramu NK, Sood B, Wig JD. Comparative evaluation of plain films, ultrasound and CT in the diagnosis of intestinal obstruction. Acta Radiol. 1999 Jul;40 (4):422-8.

23. Megibow AJ, Balthazar EJ, Cho KC, Medwid SW, Birnbaum BA, Noz ME. Bowel obstruction: evaluation with CT. Radiology. 1991 Aug;180 (2):313-8.

\section{How to cite this article?}

Mohi J.K, Kajal S, Singh T, Singh J, Kaur N. Role of imaging in evaluation of intestinal obstruction. Int J Med Res Rev 2017;5(06):593-603. doi:10.17511/ijmrr. 2017.i06.08. 